\title{
On the issue of fire hazard the fuel oil facilities of thermal power plants
}

\author{
Arkadiy V. Zakharevich ${ }^{1, \text { a }}$, and Dmitriy N. Tsymbalov ${ }^{1}$ \\ ${ }^{1}$ National Research Tomsk Polytechnic University, 634050 Tomsk, Russia
}

\begin{abstract}
The methodology and results of an experimental study sets out the law ignition of typical liquid fuel - mazut, single heated up to high temperatures metal particles and porous particles of the metal oxides. The installed dependences of the numerical values of the ignition delay times of the temperature of porous particles (obtained after the welding) steel and solid particles of regular shape. The showed influence of the shape and structure of the particles (solid and porous) on the regularity of the process of mazut ignition.
\end{abstract}

\section{Introduction}

High requirements for reliability and safety of the equipment of thermal power stations (TPS) are traditionally defined by strict rules and regulations [1,2]. The wear level is currently the main equipment of many thermal power stations of the Russian Federation is close to the maximum permissible operating standards. Moreover, there is no scientific basis of the main elements predictive modeling reliability of the power equipment of TPS. Under these conditions are particularly important factors affecting the safety and reliability of thermal power stations (including fire safety). All organic fuel used in thermal power plants are a fire hazard. Accordingly, the regulated norms and rules for handling them [1, 2]. But in spite of these provisions, fires in thermal power facilities still occur [3, 4]. Installed in recent years [5] regularities of mazut ignition indicate that the specific use of this type of fuel requires more attention to the rules of storage, handling and transportation. But so far there is no evidence to suggest that all of the factors that determine the fire hazard of fuel oil facilities of TPS, established and systematized.

It may be noted that the results of experimental [6-8] and theoretical [9-11] studies the conditions and characteristics of the liquid $[6,9,10]$ and solid $[7,8,11]$ fuels ignitions, the established the possibility of fires during the local heating (primarily single heated to a high temperature metal and nonmetallic particles $\left(T_{p}\right)$ falling on the surface of the fuel.). Temperature range of local heat sources (respectively, and fire risk) covers an area significantly smaller values $T_{p}$ compared to the temperature of the particles formed during welding and cutting metals

Well established $[12,13]$, it is possible to some ignition distillate fuels in the vapor phase under intensive heating the mixture vapor of the liquid fuel with an oxidizing agent (oxygen) for local heating of a single heated up to high (over $1000 \mathrm{C}$ ) temperatures particle.

\footnotetext{
${ }^{a}$ Corresponding author: bet@tpu.ru
} 
The aim of this paper is to analyze the results of experimental studies of the conditions of ignition of mazut at thermal power station by heated single particles.

\section{Experimental technique}

In the planning and organization of the experiment were considered possible conditions of interaction heated to a high temperature of the particles formed during the welding and cutting of metal structures, with mazut film. But this is, first, unlikely. Second, for large characteristic sizes of tanks with fuel oil, the metal particle must quickly sink without initiating combustion. Ignition of flammable liquids is possible in the event of a spill on a solid surface and formation of sufficiently thin films. For these reasons all experiments were performed with films of mazut brand T-100 with a thickness of about $2 \mathrm{~mm}$.

In a similar experimental [5-7] and theoretical studies [8-17] the main characteristic of the process was the dependence of delay time of ignition $\left(\tau_{i g n}\right)$ from the temperature of the heat source $T_{p}$. Accordingly, in the experiments, the results of which are given below, also a function of purpose was adopted by the dependence $\tau_{i g n}\left(T_{p}\right)$. In General, the methodology of the experiment was identical to that described in [5].

One of the objectives of the study was to analyze the influence of the shape and structure of particles to conditions and characteristics of ignition of mazut. Therefore, in the experiments used, steel particles in the form of a disc (diameter of $d_{p}=6^{\cdot} 10^{-3} \mathrm{~m}$, the thickness is $\left.h_{p}=3 \cdot 10^{-3} \mathrm{~m}\right)$, spheres $\left(d_{p}=6^{\cdot} 10^{-3} \mathrm{~m}\right)$, and formed after welding.

\section{The discussion of experiments' results}

Fig. 1 shows the experimental dependence $\tau_{i g n}\left(T_{p}\right)$ for the three possible configurations of particles - a heating source (disc, sphere, drop, formed after welding). The solidified porous particles formed after welding, selected (sorted) before experiments so that their area of the mid-section was as close as possible to the cross-sectional area of the particle in the form of a sphere.

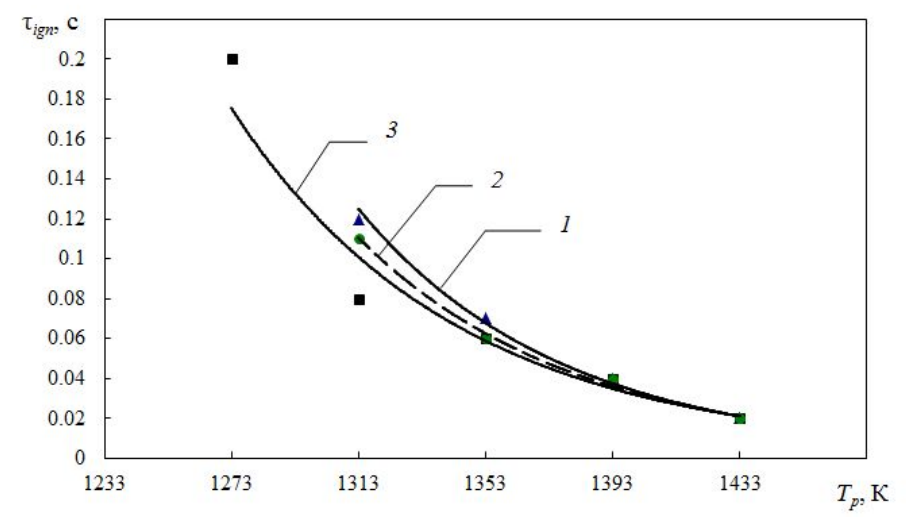

Fig. 1. Experimental dependences of mazut ignition time delay from the initial temperature of the particle: 1 - spheres $d_{p}=6^{\bullet} 10^{-3} \mathrm{~m} ; 2-\operatorname{disc} d_{p}=6^{\bullet} 10^{-3} \mathrm{~m}, h_{p}=3^{\cdot} 10^{-3} \mathrm{~m} ; 3$ - particle after welding.

The maximum error in determining the delay time in all the performed experiments did not exceed $15 \%$ (small $T_{p}$ ). A comparison of the values of $\tau_{i g n}$ obtained for typical mazut and distillate fuels - kerosene (Fig. 2). It may be noted that in all the range of initial 
temperatures particle heat sources, the time delay ignition of the mazut was less than that obtained for kerosene.

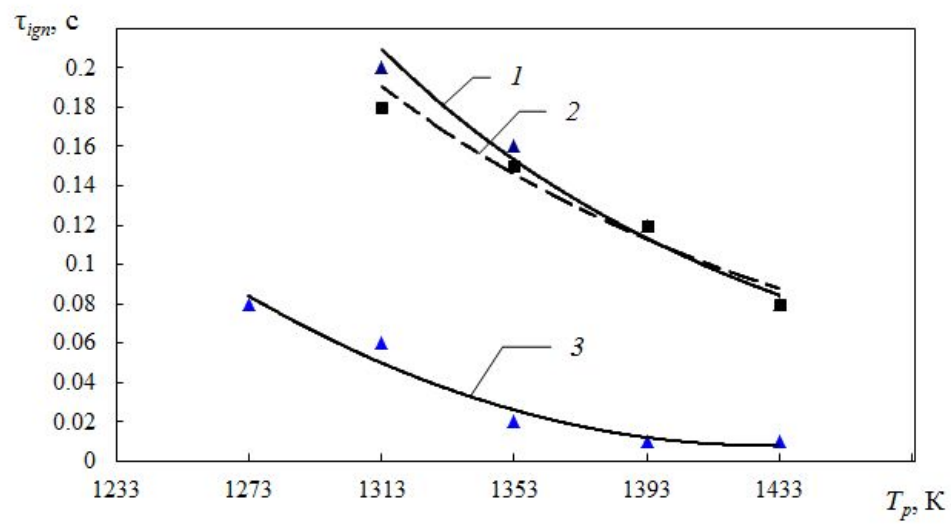

Fig. 2. Experimental dependences of kerosene ignition time delay from the initial temperature of the particle: 1 - spheres $d_{p}=6^{\cdot} 10^{-3} \mathrm{~m} ; 2-\operatorname{disc} d_{p}=6^{\cdot} 10^{-3} \mathrm{~m}, h_{p}=3^{\cdot} 10^{-3} \mathrm{M} ; 3-$ particle after welding.

It is not obvious at first glance, the ratio of the values $\tau_{i g n}$, probably due to the peculiarities of the formation of flammable vapors of these fuels. Fuel oil (mazut) refers to liquid fuels with a certain share of the solid residue (coke) of the pyrolysis process. At the stage of vaporization of the mazut consumed is significantly less compared to any distillate fuels (including kerosene) heat of phase transition per unit mass of fuel.

It should be noted that the analysis video frames experiments showed that the mazut vapor ignition occurs at a small distance from the surface of the fuel film. But the mechanism of mazut ignition quite significantly different from the corresponding mechanisms of distillate fuels. As a result, separation into fractions of low-temperature gasification residue mazut temperature increases, and the thermal decomposition starts. The mass of the nonvolatile residue amounts to $60 \%$ of the initial mass of the fuel [18]. Therefore, it can be divided into two stages of mazut ignition process. In the first step (at relatively low temperatures $(1313-1400 \mathrm{~K})$ ) the ignition of vapor occurs. In a further ignited products of thermal decomposition the second part, which is formed during heating of highmolecular fractions of the fuel. In Fig. 3 shows a typical video frames obtained in the experiment when the ignition of the film of mazut spherical particle.

a)

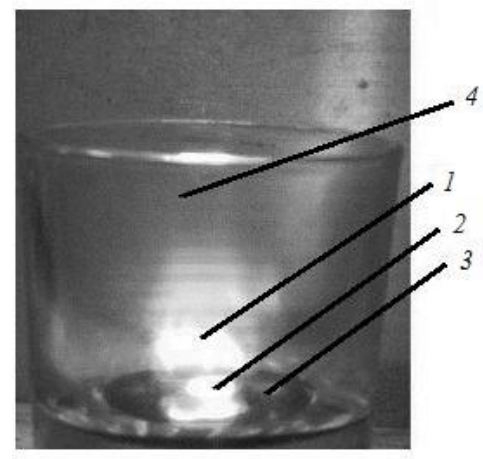

6)

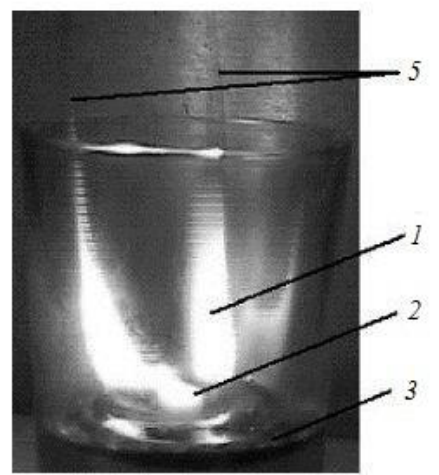

Fig. 3. Video frames of the experiment with ignition of mazut by a steel hot particle: 1 - flame; 2 hot particle; 3 - mazut; 4 - glass vessel; 5 - products of the combustion of light mazut fractions vapor. 
In experiments also found that when exposed to mazut porous particles (formed after weld) ignition occurs at temperatures almost 40 degrees lower than for particles in the form of a disk or sphere. This deviation to the marginal conditions of ignition due to the influence of the open porosity of the particles (formed after welding) on the intensity of the heat transfer to the vaporization surface. Increase heat to surface evaporation rate leads to an increase in the phase boundary temperature, and accordingly, the evaporation rate and temperature of the vapor.

Furthermore, in the pores, the conditions for the ignition of air mixture local (located at the initial instant in the pores of the particle) and products of vaporization process. Perhaps the ignition of this mixture occurs in the cross section of the particle at the "oil-to-air" section.

Also the duration of induction period and conditions ignition is affected by the low (compared to solid particles), the density of the porous particles. For this reason, the deposition rate of the porous particles, much less than monolithic. Accordingly, the duration of the period of heating the fuel in the first case, significantly more.

\section{Conclusions}

In conclusion, it should be noted that the results of the experiments illustrate the high fire hazard of mazut films on a solid (e.g. concrete or metal) surfaces, and the ability to forecast conditions and characteristics of ignition of that liquid fuel.

This study was financially supported by the Russian Science Foundation (project no. 14-3900003).

\section{References}

1. The technical operation of thermal power plants, Ministry of Energy 115 (2003)

2. RD-153-34.0-03.301-00. Guidance document "Fire safety rules for power plants". M .: JSC "Energy technologies" (2000)

3. N.I. Anikin, N.N. Bulxov, V.A. Gerish, Pozharovzrivobezopasnoct 19, 53 (2010)

4. V.D. Zahmatov, Pozharovzrivobezopasnoct 22, 63 (2013)

5. A.V. Zakharevich, G.V. Kuznetsov, V.I. Maksimov, V.F. Panin and D.S. Ravdin, Bulletin of the Tomsk Polytechnic University 313, 25 (2008)

6. N.S. Belkov, A.V. Zakharevich, G.V. Kuznetsov, Chem. Petrol. Eng. 50, 424 (2014)

7. A. V. Zakharevich, G. V. Kuznetsov, V. I. Maksimov and V. T. Kuznetsov, Combust. Expl. Shock. 44, 543 (2008)

8. A.V. Zakharevich, J. Eng. Phys. Thermophys. 87, 98 (2014)

9. O.V. Vysokomornaya, G.V. Kuznetsov, P.A. Strizhak, Russ J.Phys Chem. B 5, 668 (2011)

10. G.V. Kuznetsov, P.A. Strizhak, J. Phys Chem. B 3, 441 (2009)

11. D.O. Glushkov, G.V. Kuznetsov, P.A. Strizhak, Russ J. Phys. Chem. B 5, 1000 (2011)

12. G.V. Kuznetsov, P.A. Strizhak, J. Eng.Thermophysics 17, 224 (2008)

13. G.V. Kuznetsov, P.A. Strizhak, Combust. Explo. Shock. 46, 683 (2010)

14. G.V. Kuznetsov, G. Ya. Mamontov, G. V. Taratushkina, Combust. Explo. Shock. 40, 70 (2004)

15. G.V. Kuznetsov, G. Ya. Mamontov, G. V. Taratushkina, Khim. Fiz. 23, 67 (2004) 
16. G.V. Kuznetsov, P.A. Strizhak, J. Eng.Thermophys. 18, 162 (2009)

17. G.V. Kuznetsov, P.A. Strizhak, J. Eng.Thermophys. 18, 72 (2009)

18. B. S. Beloselsky, Fuel oil and energy technology (Power Engineering Institute, Moscow, 2005)

19. GOST 10585-99 Fuel oil, Fuel oil, Specifications (changes with 1, 2, 3) (2012) 